https://jurnal.ugm.ac.id/rubikon

\title{
THE CHALLENGE TOWARDS THE HEGEMONY OF HETERONORMATIVITY AS DEPICTED IN JENNY'S WEDDING: A PIERRE BOURDIEU'S SOCIAL REPRODUCTION THEORY
}

\author{
Lisa Okta Wulandari \\ e-mail: lisa.okta.w@mail.ugm.ac.id \\ Dewi Haryani Susilastuti \\ Universitas Gadjah Mada \\ e-mail: dewi.susilastuti@gmail.com
}

\begin{abstract}
In America, the definition of marriage has changed. The Supreme Court has legalized same-sex marriage. As the growth of LGBT people slowly continues, and they keep struggle and fight for their equality, heterosexuals might feel threatened. This study aims to know how the same-sex relationship challenges the hegemony of heteronormativity and whether or not the gender norm has been shifted as proof. This study uses Jenny's Wedding (2015). It focuses on gender position, role, and responsibility in heteronormativity and homosexuality. This study uses the sociological approach and gender theory, to see the relation between heteronormativity and the individuals also Pierre Bourdieu's social reproduction theory to see the shifting of gender norm. The finding shows that heteronormativity is used as the standard to judge, stereotype, expect things, and make assumptions. The recognition and support from society towards LGBT people and their coming out give challenges for the existenceof heterosexuals. Therefore, the contact of heteronormativity and homosexuality makes the heteronormativity no longer pure. When homosexuality affects gender norm, there must be changes in the gender norm itself.
\end{abstract}

Keywords: gender; hegemony; heteronormativity; homosexuality; same-sex relationship

DOI $\quad$ : https://doi.org/10.22146/rubikon.v6i2.61492

Available at https://jurnal.ugm.ac.id/rubikon/article/view/61492

This work is licensed under a Creative Commons Attribution-ShareAlike 4.0 International License

\section{INTRODUCTION}

Nowadays, in America the definition of marriage has been shifted officially by the Supreme Court. It has legalized the marriage
Article information

Received: 12 August, 2019

Revised: 26 August, 2019

Accepted: 9 September, 2019 of homosexuals, meaning that the country admits their existence in society. However, it is still controversial. Mostly, states have also legalized this law. However, there are counties that still ban this legalization. Also, 
support from society are varies Some of them support homosexual people through their votes, some oppose their right to get the same treatment as heterosexuals.

Jenny's Wedding (2015) was released in the same year when the law of legalization of same-sex marriage was passed. This is a lesbian movie which tells about a woman named Jenny who struggles to get the blessing from her family to marry her partner, Kitty. Through the movie, it tells how people around Jenny think about common norm in society and react to the 'coming out' of a lesbian like Jenny.

The concept of heteronormativity makes people stands with the idea of being heterosexual. It also rules the outside of heterosexuality. Even when the Supreme Court legalized the same-sex marriage, homosexuals keep struggling to get the blessing from their relatives since their family still do not admit the existence of homosexual though the law admits it. However, on other hand, the growth of them continues which might threat the existence of the heterosexuality itself.

The aims of this study are to know how the same sex relationship challenges the hegemony of heteronormativity and whether the gender norm has been shifted or not. To answer this, this study uses Jenny's Wedding as the object of material. In the analysis, this study focuses on gender position, role, and responsibility in heteronormativity and homosexuality. It also considers how the society reacts on the coming out of homosexuals, especially lesbians. It sees whether they support or recognize their existence. It also compares and contrast the gender position, role, and responsibility belongs to heteronormativity with the one applied by homosexual people. This research mixes the hegemony of heteronormativity, the process of socialization including the agents of socialization, and the shifting of gender norm in order to see the challenge for heteronormativity from homosexuals. To see this process of shifting, it considers the social reproduction concept which consist of habitus and field.

Earlier, the American Studies scholarship focus more about the national frame of reference. However, recently it has changed to the issue about the minority and the influence of them. In Post-Nationalist American Studies, the contributors "searched for the distinctive aspects of a dominant national culture -aspects that often had limited relevance for women and various minorities except as forms of hegemony and oppression" (Hulsether, 2002, p. 244). It also can be included gender studies specifically heteronormativity and homosexuality. Postnationalist, as reviewed by Ian Tyrell, "Rather than abandon the nation, they set transnational trends and influence in the context of -sometimes reinforcing- the nation or nationalism" (Tyrell, 2002, pp. 125-126). In another words, the focus on postnationalist is the cultural commodification or cultural wars.

In Pierre Bourdieu's Social Reproduction, this commodification culture is explained in the structural theory of Field, which discuss about the social context of two cultures that meet in society. They can influence each other but they also compete each other. Further, the way they are 'reinforcing' the nation can be seen through the legalization of same-sex marriage by the Supreme Court. Thus, the social reproduction 
in line with the theory Post-Nationalist. Besides, in another review, it is mentioned "that 'post' in 'post-national' is not intended to imply a developmental trajectory in which the nation state has been superseded by transnational of global formation. [..] [It highlights more on] post-national American Studies as the method than the object of analysis, [means that] it suggests that the authors' commitment to a version of American Studies [to be] more internationalist and comparative" (Adams, 2001, p. 19).

As remarked also in Yu's "How Tiger Woods lost his Stripes: Post-Nationalist American Studies as History of Race, Migration, and the Commodification of Culture" in John Carlos Rowe in Post Nationalist American Studies, "Yu suggests that nation states survives remarkably well, and points out that attacks on exploited labor in the underdeveloped world can ironically turn into Buy America campaigns that strengthen the US sense of self-defense, border-marking, difference and superiority while failing to explain how the poor of the world are going to live without trifles that their cheap labor provide" (Tyrell, 2002, p. 126). This statement proves the existence of the law of same-sex marriage in US that this law was made to make the state survives from the attack of the society demand about being equal and balance the practice with the First Amendment,

Congress shall make no law respecting an establishment of religion or prohibiting the free exercise thereof; or abridging the freedom of speech, or of the press; or the right of the people peaceably to assemble, and to petition the government for a redress of grievances." (Legal Information Institute of Cornell Law School, 2019).
Socialization is basically a process of socializing things in society. Based on Merriam Webster Dictionary, socialization is "the process beginning during childhood by which individuals acquire the values, habits, and attitudes of a society" (Merriam-Webster, 2018).

Variously, socialization is defined as

[..] by which one eventually adopts as one's own the morals, norms, values, and beliefs of one's own culture, and the roles appropriate to one's social position (McGee, 1980, p. 75), and as a process of insuring conformity to social standards by the development of individuals who will be motivated by their own desire to act in socially approved ways." (Rose, 1980, p. 44)

By the statement, it can be said that socialization is a process, unfinished process, which is always continuously established.

In socialization, there are groups support the socialization, groups that transfer the value, socialize the attitude and habit to each other which called 'agents of socialization'. The first agent of socialization is family. "Many factors affect the way family raises the children such as race, social class, religion, and other societal factors play an important role in socialization. That is why the value about gender norms, perception of race, and class related behaviors are taught by the family" (Lumen, 2018). Second agent is peer group. It is where an individual share thing according their age and interest. In institutions, such as workplace, school, or government, an individual is socialized about how to behave and follow the system. Particularly in school, the individual is socialized about the moral, what is wrong and right. Last, media is a medium where individual gets the information about many things, unlimited information with no 
defense. "Once they get the information and affected by that information, what they can do is just object about it: whether it is true, important, and expected" (Lumen, 2018). Basically, each of them has their own role in forming the characters of individuals.

Through the process of socialization and the role of the agents of socialization, thus certain value in society is formed. This kind of agreement is called consensus. According to consensus theory stated by Horton, consensus "conceptualizes society as a system of action unified at the most general level by shared value, by agreements on values (at least on modes) of communication and political organization" (Lane, 1976, p. 20). People agree to hold certain idea that regard as the normal one. When it has settled in the society, it stands by itself and becomes difficult to change. However, what makes it survives through generation to generation is the process of social reproduction.

Social reproduction, according to Bourdieu, "is the social process through which value is reproduced across generations, especially through the socializing influence of major institutions" (Stanford Center on Poverty and Inequality, 2018). In social reproduction, the dominant class has the power to impose meaning and value in society. "They are able to define their own culture as worthy of being sought and possessed and to establish it as the basis for knowledge in the education system. However, there is no way of showing that they are any better or worse than other subcultures in society" (The History Learning Site, 2018). Here, it can be said that educational institutions, formal and informal, agents of socialization, support the existence the value itself.
In social reproduction, there is called cultural capital. This supports the existence of the culture, for example the knowledge they have, materials they belong and who they are or where they work. According to Bourdieu, Cultural capital has an important role in social reproduction because inequalities in cultural capital reflect inequalities in social class. School facilitates the inequalities since it just socializes or promote the cultural capital of the dominant class. Bourdieu claims that the education is the agent of socialization has the role to impose this matter. The education system helps to maintain the dominant class existence.

Bourdieu uses a survey for his study; he claims that peoples taste, including art, films, music and food, is related both to upbringing and to education. He claims that there is a very close relationship linking cultural practices to educational capital and secondary, to social origin. Different tastes are associated with different classes, and class factions have different levels of prestige. Legitimate taste has the greatest prestige and includes serious classical music and fine art. According to Bourdieu, the education system attaches the highest value to legitimate taste and people find it easier to succeed in the education system and are likely to stay in it for longer (The History Learning Site, 2018).

In this case, it can be said that the cultural capital here refers to the heteronormativity and homosexual value. Heteronormativity belongs to the dominant class meanwhile the homosexual value belongs to the minority class. Still according to Bourdieu, there are two concepts that explain the ideal value that exists in the society and the contact between the ideal 
value and the non-ideal one: Habitus, and Field.

The habitus refers to the culture belongs to the majority of particular society. The culture which regards as the dominant one can be included as the habitus. "Keyes argues that Bourdieu's use of habitus is as a Weberian 'ideal type" (UKEssays, 2018). Everything that is considered to be normal, common, and usual refers to habitus.

The habitus [..] refers to the lifestyle, the values, the dispositions and the expectations of particular social groups. A particular habitus is developed through experience. Individuals learn in the best way by what they see in life and how to expect life. [..] The point of view of Bourdieu says "Individual have to react in particular events, many of which are novel, but they tend to do so in terms of behavior that they have come to see, as reasonable, common sense, behaviors. This means that the habitus is an infinitive capacity for generating product. This includes the idea of thought, perceptions, expressions and actions-whose limits are set by the historically and socially situated conditions of its products, taste, class and education (The History Learning Site, 2018).

Related to habitus, there is the concept of field which explains the relation between the dominant and the rival one. "The 'field' refers to the arena, or social context, in which a specific habitus may be realized; knowledge regarding the use of particular machinery may be of little use in the world of show jumping, but of uppermost importance to those involved in car manufacture" (UKEssays, 2018). In this social space, it sees the generation when the dominant community which hold on to certain value has contact with the other community with their own value. The contact between these two communities might give a conflict since both have different view of the world. As the conflict goes, there might be changes happened in society. According to conflict theory by Horton, "whereas the consensus model is geared towards the maintenance of social institution, conflict model reflects a positive attitude toward changes" (Lane, 1976 , p. 21). Hence what has been in society cannot be changed by any individuals instead of conflict appears or happened in the society itself.

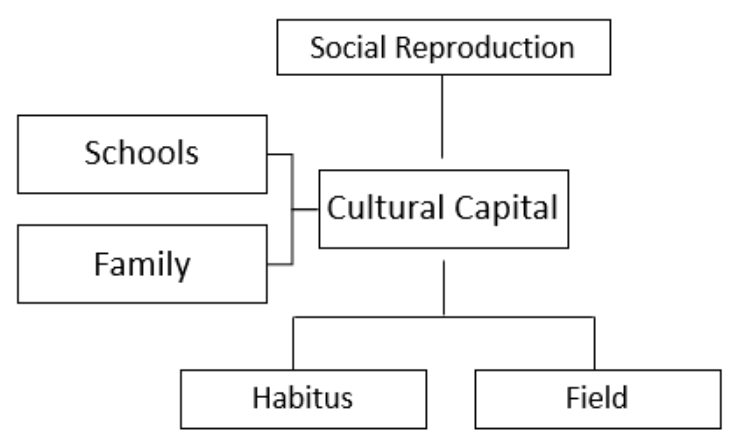

Figure 1. Theoretical Framework of Pierre Bourdieu's Social Reproduction Theory (Tzanakis, 2011, pp. 76-90)

Heteronormativity is formed by the process of socialization. Heteronormativity is understood as the standard defined by heterosexual concept. It gives an idea that an individual should act as his or her gender position and role. Heteronormativity regulates the structure of life so people can assume and expect things as it is normal and common.

While heteronormativity regulates people's sexualities, bodies, and sexual relationships (for both those nonheterosexuals on the "outside" and heterosexuals on the "inside"), it regulates nonsexual aspects of life as well. Heteronormativity also privileges a particular type of heterosexual. (Martin and Kazyak, 2009, p. 317). 
As it is explained, heteronormativity rules the sexualities, bodies, and sexual relationships. It regulates the way man and woman's act based on heterosexual view, that man should get married with woman. When they get married, the man regards as groom and woman as bride. And when they have family it consists of father, mother and children boy and girl.

Heteronormativity is one of consensus (agreement) in society about the standard of sexuality. Through heteronormativity, people define the standard of gender and sex in society. They also have expectation about the ideal norm for sexuality value and sanction for people who do not follow the rule. People agree to hold the idea that being heterosexual is normal. Hence heteronormativity is regarded as powerful side since its power structures the majority of society. Automatically, it can hegemony the less powerful side like homosexual group as minority.

The term 'hegemony' in sociology is understood as an influence of powerful sides, both can be people or things, towards the less powerful one. "When socially powerful people use their influence to convince less powerful people it is in their best interest to do what is actually in the most powerful people's best interest, that's hegemony" (Palmer, 2018).

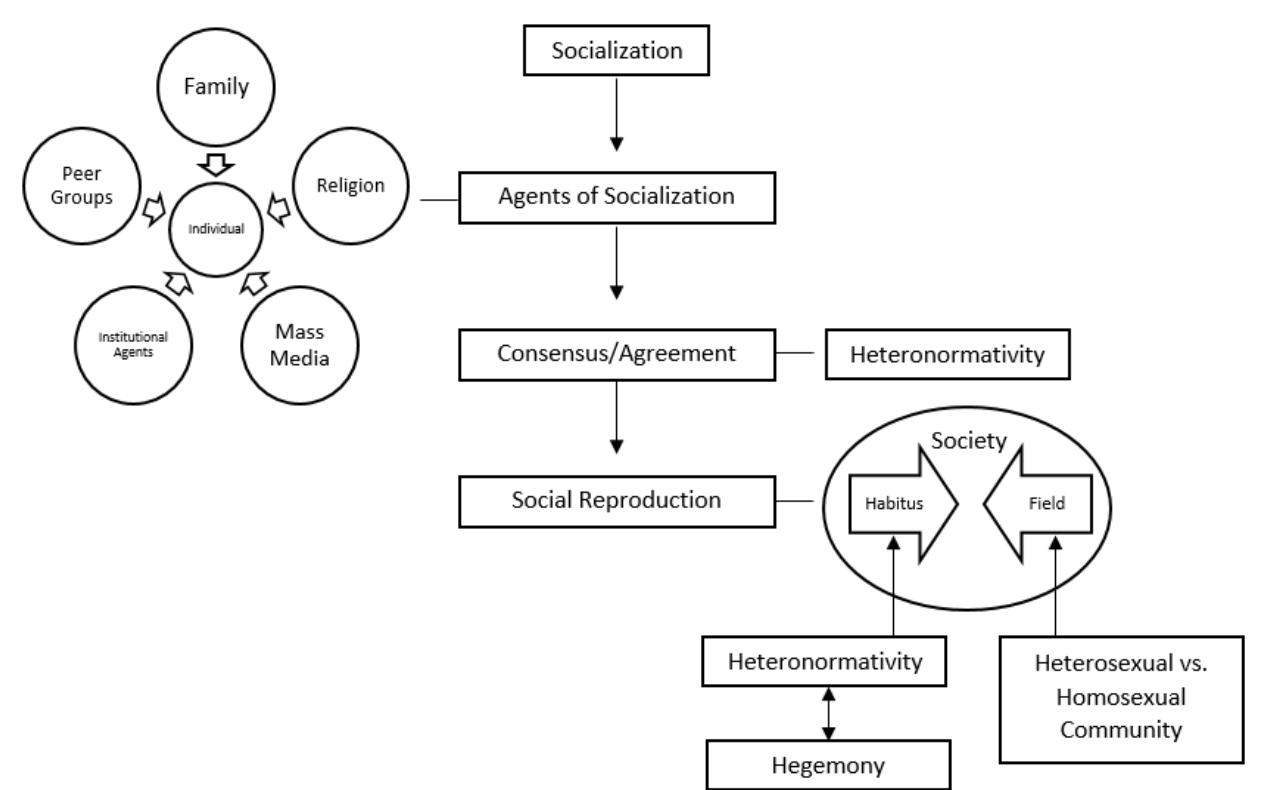

Figure 2. Theoretical framework of this study

Speaking of heteronormativity as the dominant value, it can be regarded as the habitus. Heterosexuality still remains as the majority compare to the homosexuality. Being heterosexual is regarded as 'the ideal type' or 'the normal' one for the common value. As heterosexual is seen as the common one and as the way to see and expect the life, then society will see everything through heterosexual view. Any other than heterosexual is regarded the minority. Automatically, it strengthens the heteronormativity as the dominant value and hegemony the homosexuality. 
Talking about hegemony of heteronormativity, as it can challenge the homosexual concept, the homosexual concept actually also can influence the position of heteronormativity. In an article, it mentions that "as the legal recognition of same-sex marriage increases from state to state, the dissolution of same-sex relationships has become as challenging as legally establishing them" (Martell, et al, 2011, p. 562). The difficulties experienced by the same-sex couple who move to other unions which does not recognize the same-sex marriage challenge the homonormativity. On other hand, "[A] case studies show that doing gender in a way that does not reflect biological sex can be perceived as a threat to heterosexuality" (Schilt and Westbrook, 2009, p. 442). These activities both from the heterosexual community toward homosexual community or vice versa, challenge the existence of each group. This kind of competition between heteronormativity and homonormativity can be said as the example of Bourdieu's field.

In more detail, the process of socialization does not stop to the creation of consensus which in this case is heteronormativity, but also the existence of homosexuality which challenge the heteronormativity and also the reaction of society towards the existence of both communities. Why both? Put it on this way: People who believe in heterosexual as the normal one will react on the "coming out" of homosexual people. Commonly, the reaction is a refusal. It is because "heteronormativity limited their imaginings, and their normalizing identity work confirmed the appeal and sway of conventional heterosexual models of romance" (Fields, 2001, p. 176). On other hand, people who stand in homosexual value will see heterosexual as different thing because they see the world through their homosexuality, for instance in defining gender of children. "Four of these moms strongly believed, in part due to their own experiences growing up with a nonnormative gender, that their children should be given the opportunity to be introduced to a variety of toys and clothing, regardless of how these are typically gendered in our culture" (Fields, 2001).

Speaking of heteronormativity and homonormativity, then it obviously speaks about gender.

Gender refers to socially constructed and historically variable relationships, cultural meanings, and identities through which biological sex differences become socially significant. Gender is seen, not as structurally determined, but as the outcome of women's and men's actions under historically specific conditions. More than an individual characteristic, gender refers to the social relationships between women and men that shape personal identity. In addition to being constructed and reconstructed interactionally, gender is institutionalized in, for instance, families, schools, politics, culture and ideology, the labor market and the workplace. (Laslett and Brenner, 1989, p. 382).

As it is mentioned, agents of socialization form the habit, way society see the life, etc. even included gender. Since heteronormativity and homonormativity are the two opposite communities, the way of both see each other will be different.

As heteronormativity and homonormativity are two opposite communities, then both has different values and norms. It has been mentioned that heteronormativity is regarded as the 'normal' view of life so it affects the way for most 
people see the world, included sexuality and gender. When someone is biologically female, then she is expected to do things as her gender, woman.

According to West and Zimmerman's (1987) concept of doing gender, a person's gender is not simply an aspect of who one is, but more fundamentally it is something that one does, recurrently, in interaction with others. (Berkowitz et al, 2010, p. 133).

Doing gender means not just doing or performing things according his or her gender but also about interaction.

As Chauncey (1994) has shown, by the early 1940s the defining characteristic of homosexuality had shifted from gen der inversion, expressed in sex-opposite appearances and behaviors, to sexual object choice; those engaging in same-sex sexual encounters were defined as homosexual regardless of their gendered practices, identities, and appearances. (Rosenfeld, 2009, p. 621).

Unfortunately, as it is mentioned, this life has been dominating by heteronormativity. Even homonormativity is also influenced by the heteronormativity since many researches is based on heterosexual point of view and homosexual people socialize with heterosexual people.

\section{DISCUSSION}

According to the analysis, it is found that heteronormativity, a concept defined based on heterosexual concept, is used as the standard to judge, stereotype, expect things, and making assumptions. All these four acts are interconnected to each other. In order to get the stereotype, people evaluate things and get the same pattern. According these patterns, they get stereotype. As the stereotype becomes common, the stereotype is used to expect and assume things.
Through the analysis, it can be seen the expectations and assumptions that heteronormativity makes are the stereotype of sexual relation between man and woman, what men should do and vice versa in sexual relationship, and the relation between man and man and woman and woman. It also shapes the role and responsibilities, status and position, jobs for men and women and what to wear by men and women. This norm also drives how people expect gender according their name. Hence, by society, heteronormativity is regarded as worldview which form their common sense.

All of these expectations and assumptions are formed through the process of socialization. It happens when individuals interact with the agents of socialization including family, religion, peer groups, institutional agents, and mass media. As it survives and dominates all major field, it hegemonizes both heterosexuals and homosexuals. Based on the analysis, this hegemony can be seen through the attitude and the reaction from the outside about their existences.

People who are hegemonized by heteronormativity, which in this case is homosexual people, tend to fear and not confident to admit as homosexual person or whoever being involved with homosexual people tend to deny the relation or even deny the truth that those are actually homosexuals. They lie to other people about being homosexual and feeling guilty for being different. They feel like being in a prison since they cannot express who they are. Sometimes they even blame themselves with their relatives who admit as being homosexual. When they talk to other people, they also tend to be panic and worry, suspecting that they would think badly about them. However, not just fear, this 
hegemony also can give pride to heterosexual people who has fulfilled the standard of being heterosexual.

On other hand, society who react on this matter commonly judge them and give punishment such as talking behind their backs and shunned by people. There is also possibility of gap in relation after the coming out. They even chose to leave the neighborhood to avoid the punishment from society for being homosexual. These negative responses such as gossiped, judged, regarded as not normal, might be regarded as the discriminations which refers to homophobia, the feeling of afraid toward the homosexuals' existence. When it gives more power to heteronormativity, it refers to heterosexism since it refers to the discrimination as the cause of belief that heterosexual is the normal one. But, the hegemony is also can be seen when people does not know that it does exist, when they regard the relationship between woman and woman is just a double wedding. They do not expect that both are actually a couple. However, even though the heteronormativity hegemonizes them, the recognition towards the existence of homosexual people give challenge for the existence of heterosexual since the society admits and supports the homosexual coming out.

There are two kinds of reactions from society about homosexuals' coming out: rejection and recognition. The rejections from society can be seen through the hegemony of heteronormativity above. The challenge starts from struggle first then the recognition itself. When they are struggling, they bring the moral idea about for not lying about the true self and be proud to be who you are and being confident and brave to admit that they are homosexuals.
The recognition from people itself are vary, depends on the background of characters. Young people tend more open to the coming out than the elder one. When the younger can directly accept the homosexuals, the elders need longer time to admit accept their 'coming out'. Gender also affects the way people accept the coming out. It shows that women tend compulsive then men in recognizing homosexual people.

However, what is the most challenging recognition for heteronormativity from the existence of homosexuality is the presence of guests in a same-sex wedding ceremony. It is because if they come to the party, it means they admit the marriage and support the couple which means they admit another norm beside heteronormativity, homosexuality.

Another proof that the existence of homosexual community challenges the existence of heterosexual is the shifting of gender norm. Heteronormativity affects the way gender norm determines the status, position, and role of men and women, what to wear by men and women, and human's activities. When homosexuality affects gender norm, there must be changes in gender norm itself.

According to social reproduction which has concept that value is reproduced from generation to generation, for example from grandmother to mother and then from mother to daughter, there might be difference of values from one generation to other generations since the process includes different individuals and agents of socialization which has different background. The condition outside the individuals and agents also affect the changes, for example the year when the individual lives. Structural concept of social reproduction which 
consists of habitus and field explains about this shifting.

Habitus refers to anything considered to be the common one while field is regarded as the arena of 'field' where two values meet and compete. In this case, heteronormativity is habitus since it is regarded as the normal and common one. On other hand, the meeting of heteronormativity and the value belongs to homosexual community is regarded as field.

Speaking of field or social context, the meeting happens since though both are different communities, but they live together, homosexual people as the minorities live in heterosexual environment. Homosexual people grow up by holding on heteronormativity before they decide to be homosexuals. However, since the gender norm has mixed with their homosexual behaviors, this norm cannot be said as the pure one anymore. Thus, the gender norm has been shifted.

\section{CONCLUSION}

The shifting of gender norm as the influence of homosexuality marks the challenge for heteronormativity from homosexuality. This challenge has started from the time when homosexual people struggle to be recognized by society as the way they are since though they are homosexual but do not as the way they are and still pretend to be heterosexual, they will keep using heterosexual value. When homosexuality behavior applies, it is when the challenge real happens.

It is necessary to highlight that homosexuality here is recognized and legalized, not regarded as one trueness. So, they will keep struggle and need longer time to be regarded as same as heterosexual people. Indeed, the heteronormativity might be reduced as the increasing movement of homosexuals. However, as long as homosexual people still need to be recognized and admitted as part of society, hegemony of heteronormativity will still exist.

\section{REFERENCES}

Adams, Rachel. (2001). "Review: The Worlding of American Studies" review of Literary Culture and U.S. Imperialism: From the Revolution to World War II, by John Carlos Rowe, Post-Nationalist American Studies, by John Carlos Rowe, and Postcolonial Theory and the United States: Race, Ethnicity, and Literature, by Amerjit Singh and Peter Schmidt. American Quarterly, 5(4). Retrieved July 10, 2019, from

https://www.jstor.org/stable/30041920

Berkowitz, Dana, Namita N. Manohar and Justine E. Tinkler. (2010). Walk Like a Man, Talk Like a Woman: Teaching the Social Construction of Gender, Teaching Sociology, 38(2), American Sociological Association, Retrieved January 5, 2019, from

https://www.jstor.org/stable/25677742.

Fields, Jessica. (2001). Normal Queers: Straight Parents Respond to Their Children's "Coming Out", Symbolic Interaction, 24(2). Wiley on behalf of the Society for the Study of Symbolic Interaction. Retrieved January 15, 2019 from

https://www.jstor.org/stable/10.1525/si.2 001.24.2.165

Hulsether, Mark. (2002). Book Review: John Carlos Rowe (ed.) Post-Nationalist American Studies review of Post- 
Nationalist American Studies, by John Carlos Rowe. European Journal of Cultural Studies, 5(2). Retrieved July, 10 2019, from https://doi.org/10.1177/13675494020050 020604

Lane, William C. (1976). Consensus, Conflict, and International Stratification Theories of Modernization: An Evaluation, MidAmerican Review of Sociology, 1(2). Retrieved October 6, 2018, from http:www.jstor.org/stable/23252511

Laslett, Barbara and Johanna Brenner. (1989). Gender and Social Reproduction: Historical Perspectives, Annual Review of Sociology, 15. Retrieved November 28, 2018 , from https://www.jstor.org/stable/2083231

Legal Information Institute of Cornell Law School. First Amendment. Retrieved July 10, 2019, from https://www.law.cornell.edu/constitution/ first_amendment

Lumen. Agents of Socialization. Retrieved November 15, 2018, from https://courses.lumenlearning.com/sociol ogy/chapter/agents-of-socialization/

Martell, Christopher R., et al. (2011). SameSex Relationships and Dissolution: The Connection between Heteronormativity and Homonormativity. Family Relations, 60(5). Retrieved October 17, 2018. https://www.jstor.org/stable/41403626

Martin, Karin A. and Emily Kazyak. (2009). Hetero-Romantic Love and Heterosexiness in Children's G-Tated Films. Gender and Society, 23(3). Retrieved October 17, 2018, from https://www.jstor.org/stable/20676783
Merriam-Webster, $\quad$ s. $\quad$ v. "socialization." Retrieved November 30, 2018, from https://www.merriamwebster.com/dictionary/socialization

Palmer, Nathan. Hegemony: The Haves and "Soon to Haves". Sociology in Focus. Retrieved October 17, 2018, from http://sociologyinfocus.com/tag/hegemon $\mathrm{y} /$

Rosenfeld, Dana. (2009). Heteronormativity and Homonormativity as Practical and Moral Resources: The Case of Lesbian and Gay Elders, Gender and Society, 23(5). Retrieved January 20, 2019, from https://www.jstor.org/stable/20676814

Stanford Center on Poverty and Equality. Cultural Reproduction and Social Reproduction, Stanford University. Retrieved December 5, 2018, from https://inequality.stanford.edu/publicatio ns/media/details/cultural-reproductionand-social-reproduction

The History Learning Site. Piere Bourdieu. Retrieved December 5, 2018, from https://www.historylearningsite.co.uk/soc iology/education-and-sociology/pierrebourdieu/

Tzanakis, Michael. (2011). Bourdieu's Social Reproduction Thesis and the Role of Cultural Capital in Educational Attainment: A Critical Review of Key Empirical Studies, Educate, 11(1). Retrieved May 28, 2019, from http://www.educatejournal.org/76

Tyrell, Ian. (2002). Post-Nationalist American Studies by John Carlos Rowe review of Post-Nationalist American Studies, by John Carlos Rowe. Australian Journal of American Studies, 21(1). Retrieved July 
Lisa Okta Wulandari \& Dewi Haryani Susilastuti - The Challenge towards the Hegemony of Heteronormativity as depicted in Jenny's

Wedding: A Pierre Bordieou's Social Reproduction Theory

10, 2019, from

https://www.jstor.org/stable/41053902

UKEssays.com. Bourdieu's Theory of Capital,

Habitus and Field All Answers Ltd.

Retrieved December 5, 2018, from

https://www.ukessays.com/essays/sociolo

gy/bourdieus-theory-capital-]habitus-

field-3862.php

Wasburn, Philo C. Socialization And Social Conflict, International Review of Modern Sociology, Vol. 14, No. 2 (Autumn 1984), International Journals, accessed $20 \quad$ November 2018, https://www.jstor.org/stable/23565702. 